\title{
Ononin induces cell apoptosis and reduces inflammation in rheumatoid arthritis fibroblast-like synoviocytes by alleviating MAPK and NF-KB signaling pathways
}

\author{
Yue Meng1\#, Jian Ji2\#, Xiao Xiao3, Minghan $\mathrm{Li}^{4}$, Shangbo ${ }^{3}{ }^{4}$, Youhua $\mathrm{He}^{4}$, Guojun Tong 5 and \\ Chenglong $\operatorname{Pan}^{1 \otimes}$
}

1 Department of Joint Surgery, The Fifth Affiliated Hospital of Southern Medical University, Guangzhou, Guangdong Province, 510900 , China; 2Department of Breast Surgery, The Fifth Affiliated Hospital of Southern Medical University, Guangzhou, Guangdong Province, 510900 , China; ${ }^{3}$ Department of Spine Orthopedics, Shenzhen People's Hospital, Shenzhen, Guangdong Province, 518055, China; ${ }^{2}$ Department of Spine Orthopedics, NanFang Hospital, Guangzhou, Guangdong Province, 510515, China; ${ }^{5}$ Department of Spine Orthopedics, Hangzhou Xiaoshan Hospital of TCM, Hangzhou, Zhejiang Province, 311200, China

As a kind of chronic inflammatory diseases, rheumatoid arthritis (RA) has a low cure rate and easy recurrence. It has widely reported that abnormal activation of mitogen-activated protein kinase (MAPK) and nuclear factor kappa-B (NF-KB) signaling pathways are associated with the development of RA inflammation. Blocking the inflammatory signaling pathways of rheumatoid arthritis fibroblast-like synoviocytes (RA-FLS) can delay the development of RA. Ononin is a natural isoflavone glycoside and plays a key role in modulating inflammation related signaling pathways. However, whether Ononin exerts anti-inflammatory effects on RA inflammation remains unknown. In this study, we evaluated the therapeutic effect of Ononin on RA by establishing a tumor necrosis factor a (TNF-a)-induced RA-FLS cell model. Our data confirmed that Ononin could alleviate TNF-a-induced RAFLS and MH7A cells viability, increase cell apoptosis, decrease the production of pro-inflammatory cytokines like interleukin-1 $\beta$ (IL-1 $\beta$ ) and interleukin 6 (IL-6), and further inhibit the abnormal activation of NF-KB and MAPK pathways. Our results suggested that Ononin could be a potential therapeutic agent for RA.

Key words: Rheumatoid arthritis, Ononin, rheumatoid arthritis fibroblast-like synoviocytes, MAPK, NF-KB

Received: 27 October, 2020; revised: 15 March, 2021; accepted: 07 May, 2021; available on-line: 02 June, 2021

⿶e-mail: clpan666@163.com

\#Those Authors contributed equally to this work

Acknowledgements of Financial Support: This work was supported by Research Initiative Project of Southern Medical University (Grant No.PY2017N033) and President Foundation of The Fifth Affiliated Hospital of Southern Medical University (Grant No.YZ2017MS006, Grant No.YZ2018MS002).

Abbreviations: IL-1 $\beta$, interleukin-1 $\beta$; IL-6, interleukin 6; MAPK, mitogen-activated protein kinase; NF-KB, nuclear factor kappa-B; RA, rheumatoid arthritis; RA-FLS, rheumatoid arthritis fibroblast-like synoviocytes; TNF-a, tumor necrosis factor a

\section{INTRODUCTION}

Rheumatoid arthritis (RA), one kind of serious chronic autoimmune and inflammatory diseases, is characterized by inflammation of the joints and parenchyma (Guo et al., 2018). Previous study indicates that synovium is the main lesion site of RA, abnormal synovial hyperplasia and inflammatory cells infiltrating the synovium will eventually lead to inflammatory destruction of the joint
(Buchbender et al., 2013). RA has a low cure rate and is prone to relapse, which is caused by the abnormal immune responses (Heidari, 2011). Notably, inhibiting inflammation-related pathways can delay the progression of RA (Chimenti et al., 2015). Non-steroidal anti-inflammatory drugs plus anti-rheumatic medicines and corticosteroids are often used in the first-line treatment of RA, but the therapeutic effects still remains to be improved (Kumar \& Banik, 2013). Previous study indicates rheumatoid arthritis fibroblast-like synoviocytes (RA-FLS) cells play a key role in the initiation and progression insynovitis induced RA (Bartok \& Firestein, 2010). As the inflammation occurs, RA-FLS cells produce apoptosis resistance, excessive proliferation, migration and invasion, resulting in the destruction of the joint tissue (Shi et al., 2016). Thus, exploring the apoptosis of RA-FLS caused by inflammation is of great significance for further investigating the pathogenesis of RA and improving the treatment strategy.

MAPK and NF- $x \mathrm{~B}$ signaling pathways are considered to be important signaling pathways involved in the development of RA inflammation (Yang et al., 2017). The MAPK family contains three major classes, such as JNK1/JNK2/JNK3, ERK1/ERK2and p38 (Johnson \& Lapadat, 2002). Activated MAPKs induces a series of downstream signaling cascade including ERK, JNK and p38 cascades, which implicated inregulating various cellular processes including cell survival/apoptosis, proliferation and inflammatory responses (Kim \& Choi, 2010). NF- $x \mathrm{~B}$, a collective name for dimeric transcription factors including cRel, RelA (p65), RelB, NF- $x \mathrm{~B} 1$ and $\mathrm{NF}-x \mathrm{~B} 2$, is a key factor in the transcription of many inflammatory genes (Shih et al., 2015). NF- $x$ B can be activated by a variety of pathogenic stimulation, including bacterial or viral proteins, cytokines, radiation and oxidative stress (Karin et al., 2004). Activated NF- $x$ B leads to the release of diverse pro-inflammatory factors, including MCP-1, cyclooxygenase-2 (COX-2), tumor necrosis factor $\alpha$ (TNF- $\alpha)$, IL- $1 \beta$ and IL- 6 , which are essential for the inflammatory response. (Makarov, 2001) It has also demonstrated that RA is associated with the abnormal activation of the MAPK and NF- $x \mathrm{~B}$ pathways (Liu et al., 2017).

Ononin (Formononetin 7-O-glucoside) is a natural isoflavone that widely distributed in a variety of foodborne plants such as Astragalus membranaceus, soybean, kudzu, lupine and broccoli (Dong et al., 2017). It has 
been reported that Ononin possesses anti-inflammatory effect on zebrafish model induced by lipopolysaccharide, which can reduce the production of proinflammatory cytokines like TNF- $\alpha$, IL-1 $\beta$, IL- 6 and IFN- $\gamma$, increase the expression of anti-inflammatory factor IL-10, and regulate the activity of MAPK pathway (Luo et al., 2019). In addition, Ononin can inhibit the expression of $\mathrm{NO}$, PGE2, TNF- $\alpha$, IL-1 $\beta$ and IL- 6 by inhibiting the activation of $\mathrm{I} \varkappa \mathrm{B} \alpha$ and MAPKs, and then plays an anti-inflammatory role in LPS stimulated macrophage RAW264.7 (Dong et al., 2017). Besides, Ononin is also reported to exert inhibitory and pro-apoptotic effects on cell proliferation in breast cancer cell by down-regulating PI3K/ AKT/mTOR signaling pathway (Zhang et al., 2018). However, whether Ononin has anti-inflammatory and pro-apoptotic effects on RA remains unknown.

At present, we established the TNF- $\alpha$-induced RA-FLS and MH7A cell model and found that Ononin alleviated the cell viability, increased cell apoptosis, decreased theproduction of pro-inflammatory cytokines like IL-1 $\beta$ and IL- 6 , and further inhibited the abnormal activation of NF$x \mathrm{~B}$ and MAPK pathways in TNF- $\alpha$-induced RA-FLS cells. Our results indicated that Ononin was suggested to be a promising agent for the treatment of RA.

\section{MATERIALS AND METHODS}

\section{Cell culture}

RA-FLS andMH7Awere cultured in DMEM medium with $10 \%$ FBS and $1 \%$ penicillin/streptomycin. Subsequently, RA-FLS and MH7A cells were randomly divided into 5 groups and stimulated by TNF- $\alpha(10 \mathrm{ng} /$ $\mathrm{ml}$, PeproTech) and Ononin (HY-N0270, MedChemExpress) with different concentration: 1) Control, 2-TNF- $\alpha$, 3-TNF- $\alpha+$ Ononin $(5 \mu \mathrm{M}), 4-\mathrm{TNF}-\alpha+$ Ononin $(10 \mu \mathrm{M})$, 5-TNF- $\alpha+$ Ononin $(50 \mu \mathrm{M})$.

\section{MTT assay}

Cell viability was detected by MTT (3- (4,5-dimethylthiazol-2-yl)-2,5-diphenyltetrazolium bromide)assay. Briefly, TNF- $\alpha$-induced RA-FLS and MH7A cells ( 5 groups in total described in the part of cell culture) were randomly placed into 96-well plates $\left(5 \times 10^{3} /\right.$ well $)$ and incubated for 4 days. Cells were incubated with 3-(4,5-dimethylthiazol-2-yl)-2,5diphenyltetrazolium bromide $(0.5 \mathrm{mg} / \mathrm{mL}$, Sigma) for $4 \mathrm{~h}$ at $37^{\circ} \mathrm{C}$. Subsequently, the medium were removed and cells were washed with PBS. And then $100 \mu \mathrm{L}$ dimethyl sulfoxide (DMSO) was added, and the microplate reader (BioRad, USA) at $570 \mathrm{~nm}$ was used to detect the OD value .

\section{Flow cytometry analysis}

Cell apoptosis was measured by FACS Calibur instrument (BD Biosciences, USA), equipped with CellQuest Pro 5 MacOS 9 software. Briefly, RA-FLS and MH7A $\left(1 \times 10^{5}\right.$ cells $)$ were stimulated by TNF- $\alpha(10 \mathrm{ng} / \mathrm{ml}$, PeproTech) and Ononin with various concentrations of 5 , 10 and $50 \mu \mathrm{M}$ for $48 \mathrm{~h}$. Then the collected cells were washed by cold PBS buffer, subsequently fixed with $70 \%$ alcohol under $4^{\circ} \mathrm{C}$ for $12 \mathrm{~h}$ and stained with propidium iodide under $37^{\circ} \mathrm{C}$ for $30 \mathrm{~min}$ prior to flow cytometry (BD Biosciences, USA) analysis.

\section{Enzyme-linkedimmunosorbentassay (ELISA)}

RA-FLS and MH7A cells were incubated in 6-well plates containing $2 \mathrm{~mL}$ containing $1 \times 10^{5}$ cells per well,
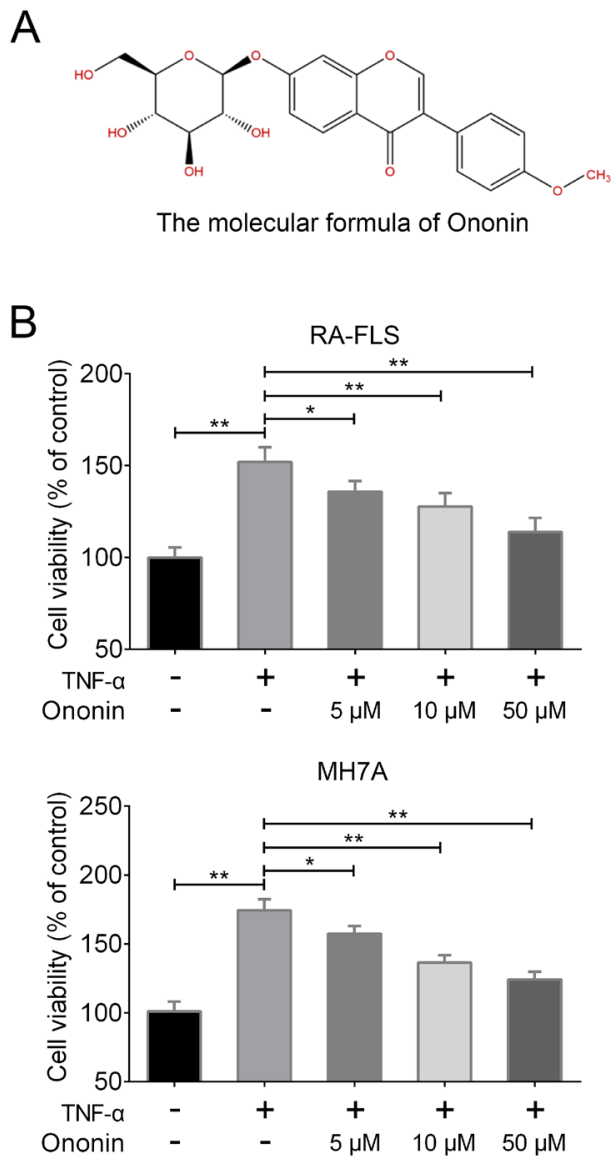

Figure 1. Ononin regulated the cell viability of TNF-a-induced RA-FLS and MH7A cells.

(A) The molecular formula of Ononin. (B) Ononin decreased the cell viability of TNF-a-induced RA-FLS and MH7A. Data were presented as means \pm S.D. ${ }^{*} p<0.05,{ }^{* *} p<0.01$.

and then stimulated by TNF- $\alpha$ (10 ng/ml, PeproTech) and Ononin with various concentrations of 5,10 and $50 \mu \mathrm{M}$ for $24 \mathrm{~h}$. Supernatants were harvested and expression level of IL-1 $\beta$ and IL-6 were analyzed by ELISA (Dakewei, Beijing, China) according to the manufacturer's instructions.

\section{Western blot assay}

Total proteins from RA-FLS and MH7A cells were collected with RIPA lysis buffer (9800, Cell Signaling, Danvers, MA) and separated by SDS-PAGE. After transferred onto PVDF membrane, membranes were blocked and subsequently incubated using the specific antibodies against GAPDH (ab9485), Bcl-2 (ab59348), Bax (ab173026), cleaved caspase-3 (ab2302), cleaved caspase-9 (ab2324), p-ERK (ab192591), ERK (ab17942), p-p38 (ab4822), p38 (ab27986), p-JNK (ab47337), JNK (ab10664), p-NF- $x \mathrm{~B}$ (ab86299) and NF- $x \mathrm{~B}$ (ab231481) purchased from Abcam (Cambridge, UK). Then the membranes were subjected to HRP-conjugated secondary antibodies for $1 \mathrm{~h}$ at room temperature. Finally, signals were visualized by an ECL kit.

\section{Statistical analysis}

Data are displayed as mean \pm S.D. The data was analyzed by GraphPad Prism (ver. 5.04). $p<0.05$ Denotes statistically significant. $*$ Indicates $p<0.05$, **indicates $p<$ 0.01 . 


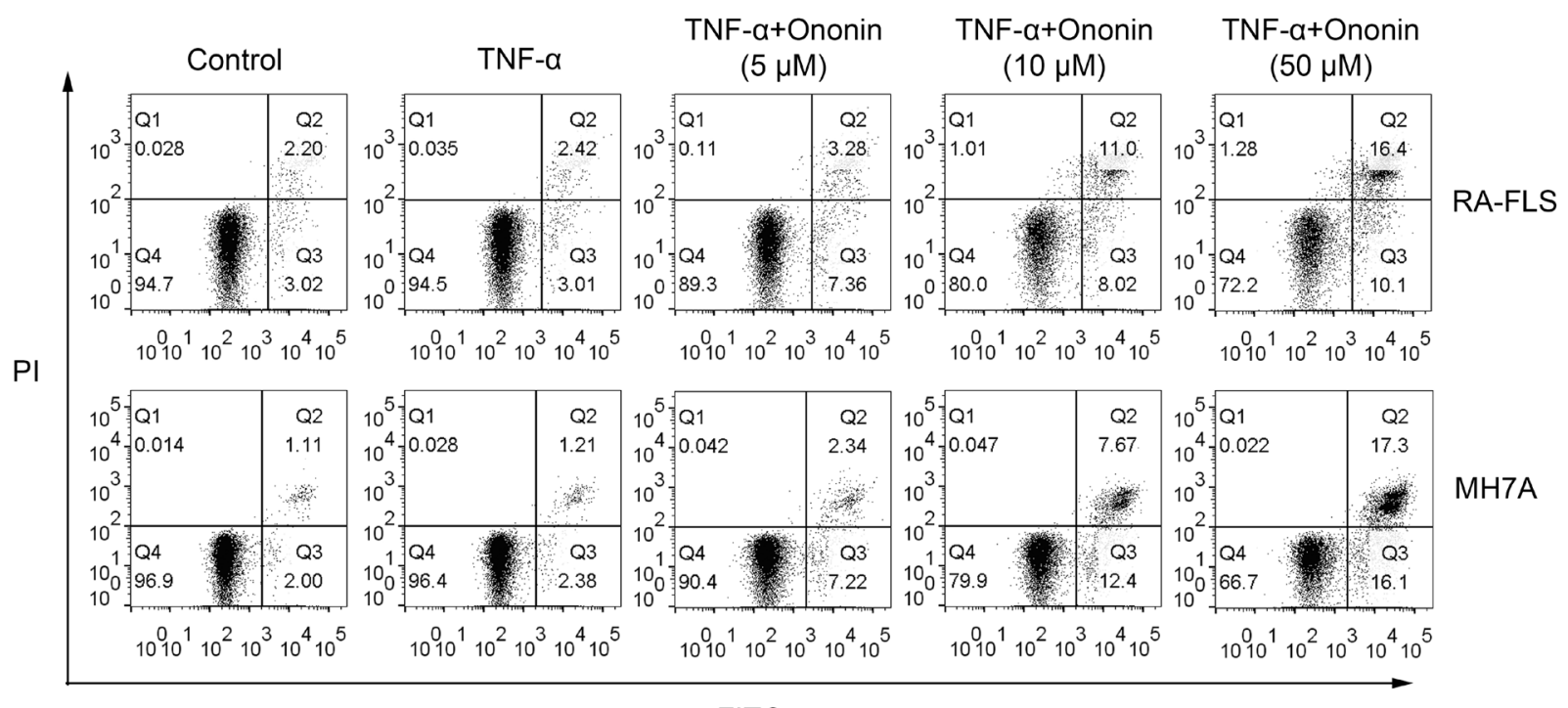

FITC
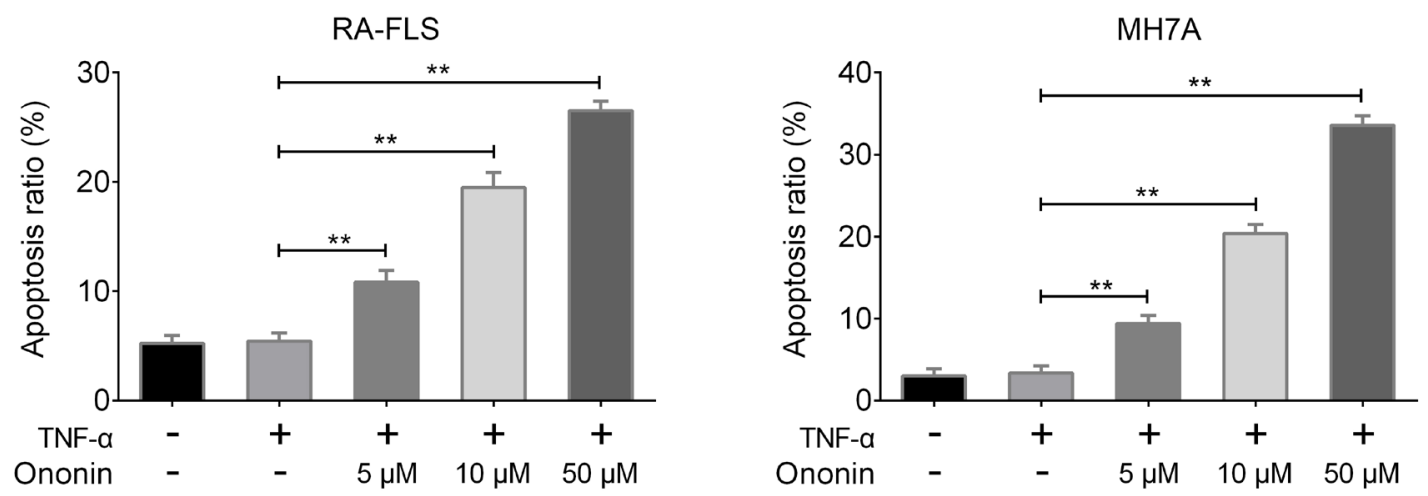

Figure 2. Ononin promoted the cell apoptosis in TNF-a-induced RA-FLS and MH7A cells. Data were presented as means \pm S.D. ${ }^{* *} p<0.01$.

\section{RESULTS}

\section{Ononin alleviated the viability in TNF- $a$-induced RA-FLS and MH7A cells}

To evaluate the therapeutic effect of Ononin, TNF- $\alpha-$ induced RA-FLS and MH7A cells model was constructed. The molecular formula of Ononin was displayed in Fig. 1A. As shown in Fig. 1B, MTT assay showed that TNF- $\alpha$ could significantly induce the cell proliferation in RA-FLS and MH7A cells $(p<0.01)$. However, compared to $\mathrm{TNF}-\alpha$ stimulation group, Ononin treatment could significantly alleviate the cell viability both in RA-FLS and MH7A cells ( $p 0.05$ and $p<0.01)$. Additionally, Ononin treatment alleviated cell viability in a concentrationdependent manner. Thus we assumed Ononin could significantly relieve TNF- $\alpha$-induced RA-FLS and MH7A cells.

\section{Ononin promoted the apoptosis inTNF-a-induced RA- FLS and MH7A cells}

The cell apoptosis was assessed by flow cytometry analysis. Compared with control group, TNF- $\alpha$ stimulation would not affect the cell apoptosis both in TNF- $\alpha$ induced RA-FLS and MH7A cells, which was consistent with previous study (Yamaguchi et al., 2004). However, after Ononin treatment, the cell apoptosis ratios were significantly increased compared to control and Ononin untreated cells (Fig. 2). These results verified Ononin may play a protective effect by attenuating the cell apoptosis in TNF- $\alpha$-induced RA-FLS and MH7A cells.

\section{Ononin regulated apoptosis protein expression in TNF- a-induced RA-FLS and MH7A cells}

To further evaluate the protective effect of Ononin on TNF- $\alpha$-induced cell proliferation in TNF- $\alpha$-induced RA-FLS and MH7A cells, the expression of cell apoptosis-related proteins was detected by using western blot assay. Previous study indicated that apoptosis-related proteins like B-cell lymphoma 2 (Bcl-2), Bcl-2 associated $\mathrm{X}$ (Bax), cleaved caspase- 3 and cleaved caspase-9, are modulated during the apoptosis process (Russo et al., 2018). The results showed that compared to control and TNF- $\alpha$-stimulated RA-FLS and MH7A cells, the apoptosis-related protein expression of $\mathrm{Bcl}-2$ was reduced by Ononin treatment, and a down-regulated tendency was found with the increase of Ononin concentration. However, the expression of Bax, Cleaved caspase- 3 and Cleaved caspase- 9 proteins was increased by Ononin treatment, and Ononin treatment caused this phenomenon in a dose dependent manner (Fig. 3). Taken togeth- 


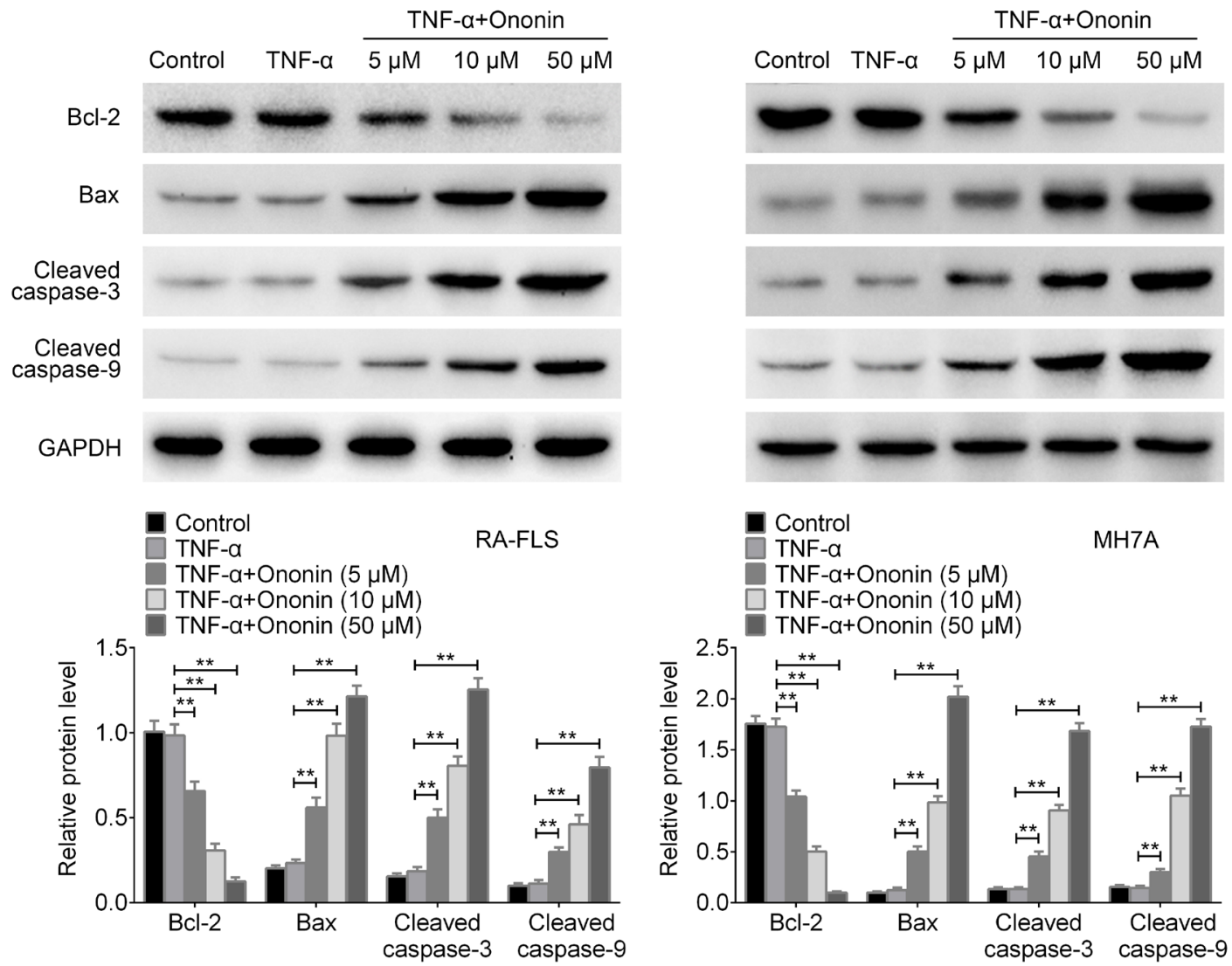

Figure 3. Ononin regulated the apoptosis-related protein expression in TNF-a-induced RA-FLS and MH7A cells. Data were presented as means \pm S.D. ${ }^{* *} p<0.01$.

A

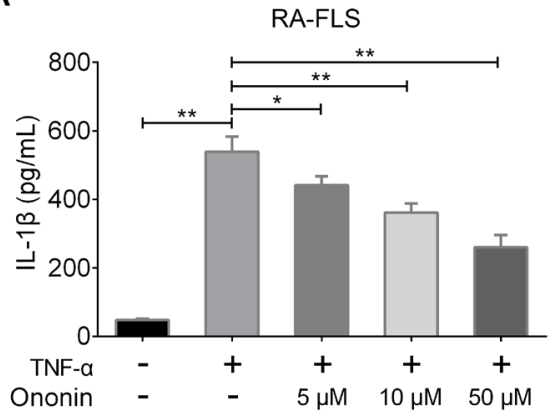

B

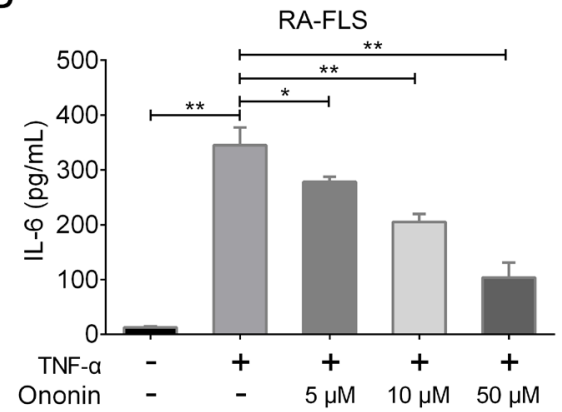

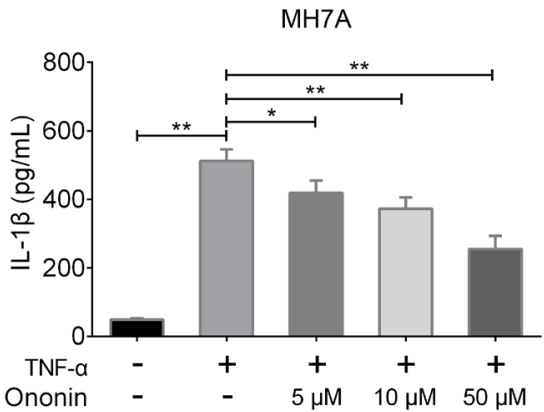

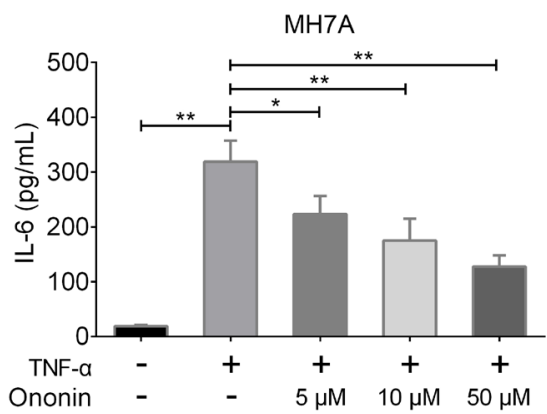

Figure 4. Ononin inhibited the levels of inflammatory cytokines in TNF-a-induced RA-FLS (A) and MH7A (B) cells. Data were presented as means \pm S.D. ${ }^{*} p<0.05,{ }^{* *} p<0.01$. 

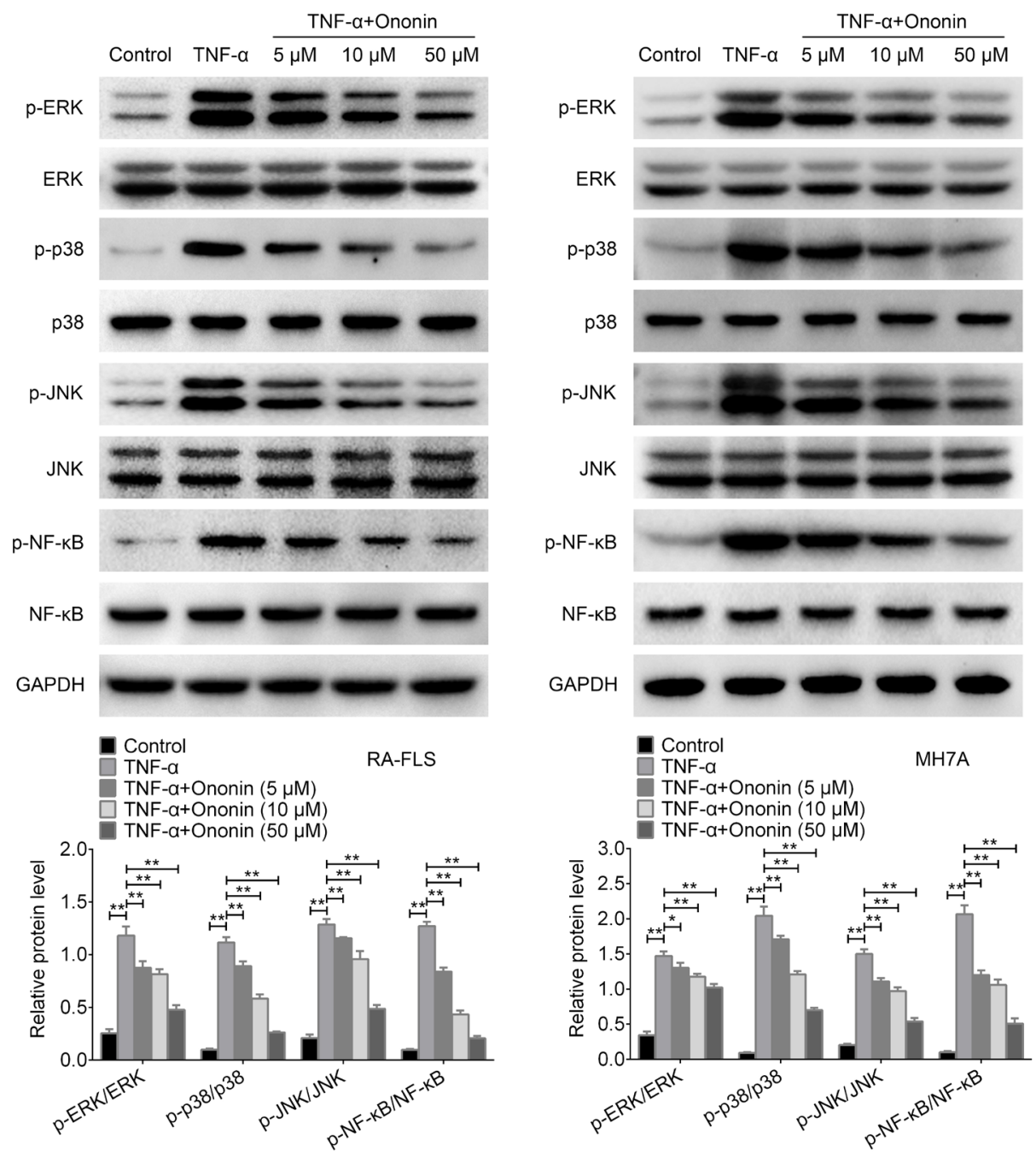

Figure 5. Ononin attenuated the activity of MAPK and NF-кB signaling pathways.

Data were presented as means \pm S.D. ${ }^{* *} p<0.01$.

er, Ononin decreased the expression of apoptosis protein $\mathrm{Bcl}-2$ and increased the expression of Bax, Cleaved caspase- 3 and Cleaved caspase- 9 proteins both in TNF$\alpha$-induced RA-FLS and MH7A cells.

\section{Ononin reduced inflammatory cytokine production in TNF-a-induced RA-FLS and MH7A cells}

Both IL-6 and IL-1 $\beta$ are important pro-inflammatory cytokines responsible for the inflammation of rheumatoid arthritis (Alunno et al., 2017). As shown in Fig. 4, $\mathrm{TNF}-\alpha$ could significantly induce the inflammatory cytokines release of IL-1 $\beta$ and IL- 6 both in RA-FLS and MH7A cells. In addition, Ononin treatment significantly down-regulated the production of IL-1 $\beta$ in TNF- $\alpha$ induced RA-FLS and MH7A cells when compared to control and $\mathrm{TNF}-\alpha$ stimulation group. And this downregulation manner showed a downward trend with the increased of Ononin concentration (Fig. 4A). Similarly, the expression of IL- 6 both in RA-FLS and MH7A cells were also reduced following Ononin challenge and displayed a dose dependent decrease (Fig. 4B). The results suggested Ononin reduced the release of inflammatory cytokines of IL- $1 \beta$ and IL- 6 both in TNF- $\alpha$-induced RAFLS and MH7A cells.

\section{Ononin regulated MAPK and NF-KB signaling pathways}

Abnormal activation of MAPK and NF- $x \mathrm{~B}$ signaling pathways are involved in the initiation and progression of RA (Yang et al., 2017). Herein, we tried to evaluate the potential therapeutic effects of Ononin on MAPK and $\mathrm{NF}-x \mathrm{~B}$ signaling pathways. Previous study reported that TNF- $\alpha$ effectively activated MAPK and NF- $x \mathrm{~B}$ signaling pathways as illustrated by increasing the expression of p-p38, p-JNK, p-ERK1/ ERK2 and p-NF- $x \mathrm{~B}$ (p-p65) (Shi \& Sun, 2018). Similarly, Ononin challenge also significantly reduced the phosphorylated level of p38 (p-p38), p-JNK, p-ERK and p-NF- $x \mathrm{~B}$ in TNF- $\alpha-$ induced RA-FLS and MH7A cells in a dose-dependent manner (Fig. 5).

\section{DISCUSSION}

As one kind of serious chronic autoimmune and inflammatory diseases, RA causes many chronic diseases including nephropathy, vasculopathy, pulmonary and cutaneous disorders as a result of the destruction of the cartilage and bone (Gupta et al., 2014). At present, about $0.5-1 \%$ of the population suffer from RA, it thus has become a serious threat leading to death (Ahmed, 2010). Even though the exact pathogenesis of RA is 
still unknown, the possible pathogenic factors of RA contain inflammation, genetic and environmental factors and so on (Mavrogeni et al., 2014). The combination of non-steroidal drugs coids, immunosuppressants and biological therapies have been widely used to treat RA in clinic (Quan et al., 2008). But RA is prone to relapse, above drugs for RA are difficult to meet clinical needs. Therefore, it is urgent to develop more effective therapeutic agents for RA. In this study, we developed a TNF- $\alpha$-induced RA-FLS and MH7A cell model, and found Ononin could obviously attenuated inflammation and promoted apoptosis in TNF- $\alpha$-induced RA-FLS and MH7A cells via MAPK and NF- $x \mathrm{~B}$ pathways. We therefore thought Ononin might be a promising agent for RA treatment.

Ononin, one kind of isoflavone, is a natural plant compound that is similar to 17- $\beta$-estradiol in chemical structure and is widely found in Fabaceae/Leguminosae family like soy beans, soy foods, and legumes (Ko, 2014). Ononin has multiple physiological functions, such as antioxidant, antimicrobial and anti-inflammatory activities (Yu et al., 2016). Additionally, people also found Ononin could promote skin growth, scaveng oxygen free radicals, inhibit lipid peroxidation, maintain the concentration of nitric oxide in blood, protect ischemia-reperfusion injury and enhance immunity (Wang et al., 2019). In view of its so many important physiological functions, we speculated that it had a special effect in fighting against RA. Our experimental results confirmed the significant effects of Ononin on the viability and apoptosis of TNF- $\alpha$-induced RA-FLS and MH7A cells.

In this study, we noticed that Ononin induced apoptosis and attenuated inflammation in TNF- $\alpha$-induced RA-FLS and MH7A cellsvia inhibiting MAPK and NF$x \mathrm{~B}$ signaling pathways. Previous study suggessted above signaling pathways play key roles in inflammatory diseases. For instance, Xia and others (Xia et al., 2018) found inhibiting NF- $x \mathrm{~B}$ pathway could significantly promote cell apoptosis and inhibit cell proliferation of human FLS cells in RA. Gao et al., found tetrandrine suppressed the developmet of RA inflammation by decreasing the release of inflammatory cytokines via blocking $\mathrm{NF}-x \mathrm{~B}$ (Gao et al., 2016). Liu et al., reported that anhuienoside $\mathrm{C}$ could ameliorate collagen-induced RA inflammation by suppressing MAPK and NF- $x$ B Pathways. (Liu et al., 2017) Similarly, we found Ononin reduced cell proliferation and improved apoptosis by blocking these pathways, further confirmed MAPK and NF- $x \mathrm{~B}$ signaling pathways were important in the progression and pathogenesis of inflammation related diseases like RA. However, the precise effects of Ononin on RA and the potential regulatory mechanisms still need further study.

In summary, we established a TNF- $\alpha$-induced RA-FLS cell model and found the effects of Ononin on apoptosis in these cells. Our data confirmed that Ononin alleviated the cell viability, increased the apoptosis and decreased the cytokines release like IL-1 $\beta$ and IL- 6 , and further inhibited the abnormal $\mathrm{NF}-x \mathrm{~B}$ and MAPK pathways activation in TNF- $\alpha$-induced RA-FLS and MH7A cells. We therefore thought Ononin could be used as a promising agent for RA treatment in the future.

\section{Acknowledgements}

Not applicable.

\section{Competing interests}

The authors state that there are no conflicts of interest to disclose.

\section{Ethics approval}

Not applicable.

\section{Statement of Human and Animal Rights}

Not applicable.

\section{Statement of Informed Consent}

Not applicable.

\section{Availability of data and materials}

All data generated or analyzed during this study are included in this published article.

\section{Authors' contributions}

Yue Meng and Jian Ji designed the study, supervised the data collection, Xiao Xiao, Minghan Li and Shangbo Niu analyzed the data, interpreted the data, Youhua He, Guojun Tong and Chenglong Pan prepare the manuscript for publication and reviewed the draft of the manuscript. All authors have read and approved the manuscript.

\section{REFERENCES:}

Ahmed S (2010) Green tea polyphenol epigallocatechin 3-gallate in arthritis: progress and promise. Arthritis Res Ther 12: 208. https://doi. org/10.1186/ar2982

Alunno A, Carubbi F, Giacomelli R, Gerli R (2017) Cytokines in the pathogenesis of rheumatoid arthritis: new players and therapeutic targets. BMC Rheumatol. 1: 3. https://doi.org/10.1186/s41927-0170001-8

Bartok B, Firestein GS(2010) Fibroblast-like synoviocytes: key effector cells in rheumatoid arthritis. Immunol Rev 233: 233-255. https://doi. org/10.1111/j.0105-2896.2009.00859.x

Buchbender C, Ostendorf B, Mattes-György K, Miese F, Wittsack HJ, Quentin M, Specker C, Schneider M, Antoch G, Müller HW, Scherer A (2013) Synovitis and bone inflammation in early rheumatoid arthritis: high-resolution multi-pinhole SPECT versus MRI. Diagn Interv Radiol 19: 20-24. https://doi.org/10.4261/1305-3825. DIR.5922-12.1

Chimenti MS, Triggianese P, Conigliaro P, Candi E, Melino G, Perricone $\mathrm{R}$ (2015) The interplay between inflammation and metabolism in rheumatoid arthritis. Cell Death Dis 6: e1887. https://doi. org/10.1038/cddis.2015.246

Dong L, Yin L, Zhang Y, Fu X, Lu J (2017) Anti-inflammatory effects of ononin on lipopolysaccharide-stimulated RAW 264.7 cells. Mol Immunol 83: 46-51. https://doi.org/10.1016/j.molimm.2017.01.007

Gao LN, Feng QS, Zhang XF, Wang QS, Cui YL (2016) Tetrandrine suppresses articular inflammatory response by inhibiting pro-inflammatory factors via NF-kappaB inactivation. J Orthop Res 34: 15571568. https://doi.org/10.1002/jor.23155

Guo Q, Wang Y, Xu D, Nossent J, Pavlos NJ, Xu J (2018) Rheumatoid arthritis: pathological mechanisms and modern pharmacologic therapies. Bone Res 6: 15. https://doi.org/10.1038/s41413-018-00169

Gupta M, Sasmal S, Mukherjee A (2014) Therapeutic effects of acetone extract of Saraca asoca seeds on rats with adjuvant-induced arthritis via attenuating inflammatory responses. ISRN Rheumatol 2014: 959687. https://doi.org/10.1155/2014/959687

Heidari B (2011) Rheumatoid arthritis: Early diagnosis and treatment outcomes. Caspian I Intern Med 2: 161-170

Johnson GL, Lapadat R (2002) Mitogen-activated protein kinase pathways mediated by ERK, JNK, and p38 protein kinases. Science 298: 1911-1912. https://doi.org/10.1126/science.1072682

Karin M, Yamamoto Y, Wang QM (2004) The IKK NF-kappa B system: a treasure trove for drug development. Nat Rev Drug Discov 3: 17-26. https://doi.org/10.1038/nrd1279

Kim EK, Choi EJ (2010) Pathological roles of MAPK signaling pathways in human diseases. Biochim Biophys Acta 1802: 396-405. https://doi.org/10.1016/j.bbadis.2009.12.009

Ko KP (2014) Isoflavones: chemistry, analysis, functions and effects on health and cancer. Asian Pac J Cancer Prev 15: 7001-7010. https://doi.org/10.7314/apjcp.2014.15.17.7001

Kumar P, Banik S (2013) Pharmacotherapy options in rheumatoid arthritis. Clin Med Insights Arthritis Musculoskelet Disord 6: 35-43. https://doi.org/10.4137/CMAMD.S5558 
Liu Q, Xiao XH, Hu LB, Jie HY, Wang Y, Ye WC, Li MM, Liu Z (2017) Anhuienoside C ameliorates collagen-induced arthritis through inhibition of MAPK and NF-kappaB signaling pathways. Front Pharmacol 8: 299. https://doi.org/10.3389/fphar.2017.00299

Luo L, Zhou J, Zhao H, Fan M, Gao W (2019) The anti-inflammatory effects of formononetin and ononin on lipopolysaccharide-induced zebrafish models based on lipidomics and targeted transcriptomics. Metabolomics 15: 153. https://doi.org/10.1007/s11306-019-1614-2

Makarov SS (2001) NF-kappa B in rheumatoid arthritis: a pivotal regulator of inflammation, hyperplasia, and tissue destruction. Arthritis Res 3: 200-206. https://doi.org/10.1186/ar300

Mavrogeni S, Dimitroulas T, Gabriel S, Sfikakis PP, Pohost GM, Kitas GD (2014) Why currently used diagnostic techniques for heart failure in rheumatoid arthritis are not enough: the challenge of cardiovascular magnetic resonance imaging. Rev Cardiovasc Med 15: 320-331. PMID: 25662926

Quan LD, Thiele GM, Tian J, Wang D (2008) The development of novel therapies for rheumatoid arthritis. Expert Opin Ther Pat 18: 723-738. https://doi.org/10.1517/13543776.18.7.723

Russo A, Cardile V, Graziano ACE, Avola R, Bruno M, Rigano D (2018) Involvement of $\mathrm{Bax}$ and $\mathrm{Bcl}-2$ in induction of apoptosis by essential oils of three Lebanese salvia species in human prostate cancer cells. Int J Mol Sci 19: https://doi.org/10.3390/ijms19010292

Shi DL, Shi GR, Xie J, Du XZ, Yang H (2016) MicroRNA-27a inhibits cell migration and invasion of fibroblast-like synoviocytes by targeting follistatin-like protein 1 in rheumatoid arthritis. Mol Cells 39: 611-618. https://doi.org/10.14348/molcells.2016.0103

Shi JH, Sun SC (2018) Tumor necrosis factor receptor-associated factor regulation of nuclear factor kappaB and mitogen-activated protein kinase pathways. Front Immunol 9: 1849. https://doi.org/10.3389/ fimmu.2018.01849
Shih RH, Wang CY, Yang CM (2015) NF-kappaB signaling pathways in neurological inflammation: a mini review. Front Mol Neurosci 8: 77. https://doi.org/10.3389/fnmol.2015.00077

Wang Y, Liu L, Ma Y, Guo L, Sun Y, Liu Q, Liu J (2019) Chemical discrimination of Astragalus mongholicus and Astragalus membranaceus based on metabolomics using UHPLC-ESI-Q-TOF-MS/MS Approach. Molecules 24: https://doi.org/10.3390/molecules24224064

Xia ZB, Meng FR, Fang YX, Wu X, Zhang CW, Liu Y, Liu D, Li GQ, Feng FB, Qiu HY (2018) Inhibition of NF-kappaB signaling pathway induces apoptosis and suppresses proliferation and angiogenesis of human fibroblast-like synovial cells in rheumatoid arthritis. Medicine (Baltimore) 97: e10920. https://doi.org/10.1097/ MD.0000000000010920

Yamaguchi N, Kubo C, Masuhiro Y, Lally ET, Koga T, Hanazawa S (2004) Tumor necrosis factor alpha enhances Actinobacillus actinomycetemcomitans leukotoxin-induced HL-60 cell apoptosis by stimulating lymphocyte function-associated antigen 1 expression. Infect Immun 72: 269-276. https://doi.org/10.1128/iai.72.1.269-276.2004

Yang G, Li S, Yuan L, Yang Y, Pan MH (2017) Effect of nobiletin on the MAPK/NF-kappaB signaling pathway in the synovial membrane of rats with arthritis induced by collagen. Food Funct 8: 46684674. https://doi.org/10.1039/c7fo01311f

Yu J, Bi X, Yu B, Chen D (2016) Isoflavones: anti-inflammatory benefit and possible caveats. Nutrients 8: https://doi.org/10.3390/ nu 8060361

Zhang HW, Hu JJ, Fu RQ, Liu X, Zhang YH, Li J, Liu L, Li YN, Deng Q, Luo QS, Ouyang Q, Gao N (2018) Flavonoids inhibit cell proliferation and induce apoptosis and autophagy through downregulation of PI3Kgamma mediated $\mathrm{PI} 3 \mathrm{~K} / \mathrm{AKT} / \mathrm{mTOR} / \mathrm{p} 70 \mathrm{~S} 6 \mathrm{~K} /$ ULK signaling pathway in human breast cancer cells. Sci Rep 8: 11255. https://doi.org/10.1038/s41598-018-29308-7 